Contents List available at VOLKSON PRESS

Intelligent Computing and Information Engineering (ICIE )

DOI : http://doi.org/10.26480/icie.01.2017.56.59

Journal Homepage: : https://www.intelcomp-design.com/

\title{
FUZZY COMPREHENSIVE EVALUATION OF CONSTRUCTION SCHEDULE RISK OF WATER CONSERVANCY PROJECT BASED ON TRIGONOMETRIC NUMBER FUZZY- AHP
}

Hong Wenxia*, Han Yan, Qian Jinyu

Shandong Qingdao economic and technological development zone along the Yangtze river middle road no. 2 in Qingdao university of technology, China *Corresponding author email: 734256936@qq.com

This is an open access article distributed under the Creative Commons Attribution License, which permits unrestricted use, distribution, and reproduction in any medium, provided the original work is properly cited

\section{ARTICLE DETAILS}

\section{Article History:}

Received 12 May2017

Accepted 12 July 2017

Available online 14 September 2017

\section{Keywords:}

Triangular number Fuzzy-AHP model, Fuzzy comprehensive evaluation method, Water conservancy project construction schedule risk, Preventive measures.

\section{ABSTRACT}

The research of water conservancy project construction schedule risk analysis, risk factors, pre-human control of controllable factor and uncontrollable factors for the development of response measures, the probability of risk reduction, to plays a very important role in successful completion of water conservancy project. In this regard, according to the actual situation of water conservancy projects and combined with relevant literature, the paper establishes 7 first level indexes and 22 two level indexes that affect the construction schedule risk of water conservancy projects. Then, the triangular number Fuzzy-AHP model is constructed to calculate the weight of risk factors, and the fuzzy comprehensive evaluation method is used to evaluate the risk. In the Hui Xian section of the middle route of South to north water diversion culvert Yu He river protection wear reinforcement engineering for example, the higher the risk, the greater the weight factors, take preventive measures to reduce the risk, to control the total construction schedule risk, provides a reasonable way to control for the construction of water conservancy project schedule risk.

\section{Introduction}

Large and medium-sized water conservancy project long construction period, large investment, complex technology, and is influenced by social and natural environment, changes in national policy, all parties involved in the project construction stage, all kinds of uncertainty, making progress risk. Therefore, it is very important to study the construction schedule risk of water conservancy project.

Sun Shuxia established a multi-level fuzzy comprehensive evaluation model, evaluated the owner risk of water conservancy and hydropower projects, and proved the feasibility of the model by an example [1]. Liu Yongqiang established a fuzzy comprehensive evaluation method of multi-level fuzzy AHP method based on Evaluation and management of water conservancy project cost risk, through the practical application, and achieved go od results in cost management [2]. Zhang Xiaonan uses multi-level fuzzy comprehensive evaluation method to evaluate the duration risk of large-scale water conservancy project, and uses specific cases to prove its rationality [3]. The above methods have proved that the fuzzy comprehensive evaluation method for risk assessment of water conservancy project, but the methods of determining weight, the latter two while recognizing the shortcomings of AHP method is subjective, and its improvement, but in the theoretical description and specific application is very vague, hinders the application of risk assessment model in practical engineering the.

In view of this, based on AHP method is introduced based on triangular fuzzy number, triangle number of Fuzzy-AHP model, AHP method to weaken subjective strength, calculate the weight factor to influence the construction schedule risk, and use fuzzy comprehensive evaluation method to evaluate the risk of water conservancy project construction schedule, provide reasonable and viable methods the evaluation for the construction of water conservancy project schedule risk.

\section{ESTABLISHMENT OF RISK INDEX SYSTEM}

According to the source of risk, the construction schedule risk of water conservancy project includes the influence of exterior society and environment, and the risk of project participant. According to references, research and engineering practice related factors, follow the feasibility, rationality and scientific principle, establish water conservancy project construction schedule risk index system, see Table 1 [3-5].

Table 1: The index system of Water conservancy project construction schedule risk

\begin{tabular}{ll}
\hline First level index & Two level index \\
\hline Environmental risks $E_{1}$ & geological conditions $F_{1}$ \\
& hydrologic condition $F_{2}$ \\
& Weather change $F_{3}$ \\
\hline
\end{tabular}




\begin{tabular}{ll}
\hline social risk $E_{2}$ & Policy change $F_{4}$ \\
& Market economy change $F_{5}$ \\
Owner risk $E_{3}$ & Management ability $F_{6}$ \\
& Contract and performance capacity $F_{7}$ \\
& Financial capability $F_{8}$ \\
& Engineering change $F_{9}$ \\
& Managerial ability $F_{10}$ \\
& Construction safety risk $F_{11}$ \\
& Improper use of Engineering funds $F_{12}$ \\
& Lack of machinery and equipment $F_{13}$ \\
& Risk of new technology and process $F_{14}$ \\
& Design errors or defects $F_{15}$ \\
& Design change $F_{16}$ \\
Design risk $E_{5}$ & Professional competence $F_{17}$ \\
& Ability to cope with emergencies $F_{18}$ \\
Supervision risk $E_{6}$ & Communication and coordination ability $F_{19}$ \\
& Material quality $F_{20}$ \\
& Material price $F_{21}$ \\
& Supply capability $F_{22}$ \\
\hline & \\
&
\end{tabular}

\section{FUZZY-AHP WEIGHT DETERMINATION METHOD}

Triangular fuzzy number is applied to the analytic hierarchy process, Fuzzy-AHP model is constructed by using this model, the comprehensive weight calculation table of 22 indexes in 1, the greater the weight, the degree of impact on construction schedule risk is bigger. The specific steps of the Fuzzy-AHP model are as follows:

(1)Structural fuzzy judgment matrix

Definition1: The fuzzy number on the set field is $M, \quad M$ Membership function For:

$\mu_{m}(x)=\left\{\begin{array}{cc}\frac{x-l}{m-l} & x \in[l, m] \\ \frac{x-u}{m-u} & x \in[m, u] \\ 0 & \text { other }\end{array}\right.$

In style: $1 、 U$ Upper and lower bounds of representation, $I \leq m \leq u \circ m$ 为 $M$

$D=\left[\begin{array}{llll}\left(l_{11}, m_{11}, u_{11}\right) & \left(I_{12}, m_{12}, u_{12}\right) & \ldots & \left(I_{1 n}, m_{1 n}, u_{1 n}\right) \\ \left(I_{21}, m_{21}, u_{21}\right) & \left(I_{22}, m_{22}, u_{22}\right) & \ldots & \left(I_{2 n}, m_{2 n}, u_{2 n}\right) \\ \ldots & \ldots & \ldots & \ldots \\ \left(I_{n 1}, m_{n 1}, u_{n 1}\right) & \left(I_{n 2}, m_{n 2}, u_{n 2}\right) & \ldots & \left(I_{n n}, m_{n n}, u_{n n}\right)\end{array}\right]$

$M_{i j}=\left(l_{i j}, m_{i j}, u_{i j}\right) \quad i, j=1,2, \cdots, n:$

$D=\left[\begin{array}{llll}M_{11} & M_{12} & \cdots & M_{1 n} \\ M_{21} & M_{22} & \cdots & M_{2 n} \\ \cdots & \cdots & \cdots & \cdots \\ M_{n 1} & M_{n 2} & \cdots & M_{n n}\end{array}\right]$

(2)Calculate the weight of each index

$D_{i}=\sum_{j=1}^{n} M_{i j} \Theta\left[\sum_{k=1}^{n} \sum_{j=1}^{n} M_{k j}\right]=\left(\frac{\sum_{j=1}^{n} I_{i j}}{\sum_{k=1}^{n} \sum_{j=1}^{n} u_{i j}}, \frac{\sum_{j=1}^{n} m_{i j}}{\sum_{k=1}^{n} \sum_{j=1}^{n} m_{i j}}, \frac{\sum_{j=1}^{n} u_{i j}}{\sum_{k=1}^{n} \sum_{j=1}^{n} I_{i j}}\right)$ 


$$
V\left(D_{1} \geq D_{2}\right)=\left[\frac{l_{2}-u_{1}}{\left(m_{1}-u_{1}\right)-\left(m_{2}-I_{2}\right)}\right] \wedge 1
$$

$d_{i}=\min V\left(D_{i} \geq D_{j}\right) \quad j=1,2, \cdots, n$ 且 $k \neq i$

$$
W=\left(W_{1}, W_{2}, \cdots W_{n}\right)=\left(\frac{d_{1}}{\sum_{i=1}^{n} d_{i}}, \frac{d_{2}}{\sum_{i=1}^{n} d_{i}}, \cdots, \frac{d_{n}}{\sum_{i=1}^{n} d_{i}}\right)
$$

(3)Calculate the comprehensive weight of two indicators

$$
W_{1}=W_{F_{1}} \times W_{E_{1}}
$$

\section{EXAMPLE ANALYSES}

Huixian section of the middle route of South to north water diversion culvert river river wear protection and reinforcement engineering is an important part of South to North Water Diversion Project, located in the central line project main canal of IV canal, is located in Huixian City, Henan province. Culvert start stop pile No. IV70+951.4 to IV71+562.4, the building is 611 by the inlet transition section of the check gate, culvert pipe, import, export and export figure control gate gradient section. Horizontal projection of hole length 450 . The design flow of 260 culverts, increasing the flow rate of 310 . Design head 0.24 , hole 3 hole, single hole size $7 * 8.2$ (width * height). In order to ensure the construction progress, the risk of construction stage is analyzed.

(1) According to table 1 evaluation index system, ask 3 authoritative experts in this field to carry on the judgment of triangular fuzzy number. To calculate the weight of the hierarchical elements, for example, the specific content is shown in table 2 .

Table 2: The judgment matrix of elements in $E_{4}$ level

\begin{tabular}{cccccc}
\hline & $F_{10}$ & $F_{11}$ & $F_{12}$ & $F_{13}$ & $F_{14}$ \\
\hline$F_{10}$ & $(1,1,1)$ & $(1 / 4,1 / 3,1 / 2)$ & $(1,2,3)$ & $(1 / 4,1 / 3,1 / 2)$ & $(1 / 4,1 / 3,1 / 2)$ \\
& $(1,1,1)$ & $(1 / 3,1 / 2,1)$ & $(1,2,3)$ & $(1 / 3,1 / 2,1)$ & $(1 / 3,1 / 2,1)$ \\
& $(1,1,1)$ & $(1 / 4,1 / 3,1 / 2)$ & $(1,2,3)$ & $(1 / 4,1 / 3,1 / 2)$ & $(1 / 4,1 / 3,1 / 2)$ \\
$F_{11}$ & $(2,3,4)$ & $(1,1,1)$ & $(2,3,4)$ & $(1,2,3)$ & $(1,1,1)$ \\
& $(1,2,3)$ & $(1,1,1)$ & $(2,3,4)$ & $(1,2,3)$ & $(1,1,1)$ \\
& $(2,3,4)$ & $(1,1,1)$ & $(2,3,4)$ & $(1,2,3)$ & $(1,1,1)$ \\
$F_{12}$ & $(1 / 3,1 / 2,1)$ & $(1 / 4,1 / 3,1 / 2)$ & $(1,1,1)$ & $(1 / 3,1 / 2,1)$ & $(1 / 4,1 / 3,1 / 2)$ \\
& $(1 / 3,1 / 2,1)$ & $(1 / 4,1 / 3,1 / 2)$ & $(1,1,1)$ & $(1 / 3,1 / 2,1)$ & $(1 / 4,1 / 3,1 / 2)$ \\
& $(1 / 3,1 / 2,1)$ & $(1 / 4,1 / 3,1 / 2)$ & $(1,1,1)$ & $(1,1,1)$ & $(1 / 4,1 / 3,1 / 2)$ \\
$F_{13}$ & $(2,3,4)$ & $(1 / 3,1 / 2,1)$ & $(1,2,3)$ & $(1,1,1)$ & $(1,1,1)$ \\
& $(1,2,3)$ & $(1 / 3,1 / 2,1)$ & $(1,2,3)$ & $(1,1,1)$ & $(1,1,1)$ \\
& $(2,3,4)$ & $(1 / 3,1 / 2,1)$ & $(1,1,1)$ & $(1,1,1)$ & $(1,1,1)$ \\
$F_{14}$ & $(2,3,4)$ & $(1,1,1)$ & $(2,3,4)$ & $(1,1,1)$ & $(1,1,1)$ \\
& $(1,2,3)$ & $(1,1,1)$ & $(2,3,4)$ & $(1,1,1)$ & $(1,1,1)$ \\
& $(2,3,4)$ & $(1,1,1)$ & $(2,3,4)$ & $(1,1,1)$ & $(1,1,1)$ \\
\hline
\end{tabular}

(2) According to formula 6, fuzzy comprehensive evaluation is carried out.

$\left(b_{1}, b_{2}, b_{3}, b_{4}, b_{5}\right)=W \circ R=(0.154,0.291,0.281,0.170,0.104)$

\section{CONCLUSION}

Iangular number Fuzzy-AHP model is an improvement to the traditional AHP method, the concept of triangular fuzzy number is introduced to the analytic hierarchy process, weaken the effect of simple subjective scores produced by the quantitative risk factors is more reasonable.

\section{REFERENCES}

[1] Shuxia, S. 2008. Application of Multi Level Fuzzy Comprehensive Risk Assessment Model in Hydraulic Engineering (Hydropower Energy Science, China). 
[2] Yongqiang, L., Hongrui, Z., Bijun, Q. 2009. Water Conservancy Project Cost Risk Management research based on FAHP (Hydropower Energy Science, China).

[3] Xiaonan, Z. 2015. Study on Comprehensive Evaluation of Duration Risk Based on Fuzzy Mathematics (Dalian University of Technology, China).

[4] Jianhui, G., Lijun, F. 2016. Fuzzy Comprehensive Evaluation of Water Conservancy Project Construction Schedule Risk Based on AHP- Entropy Method (Hydropower Energy Science, China).

[5] Xiaowen, Y. 2016. Risk Analysis and Evaluation of Water Conservancy Project During Construction Period Based on Fuzzy Theory (North China University of Water Conservancy and Hydropower,China). 